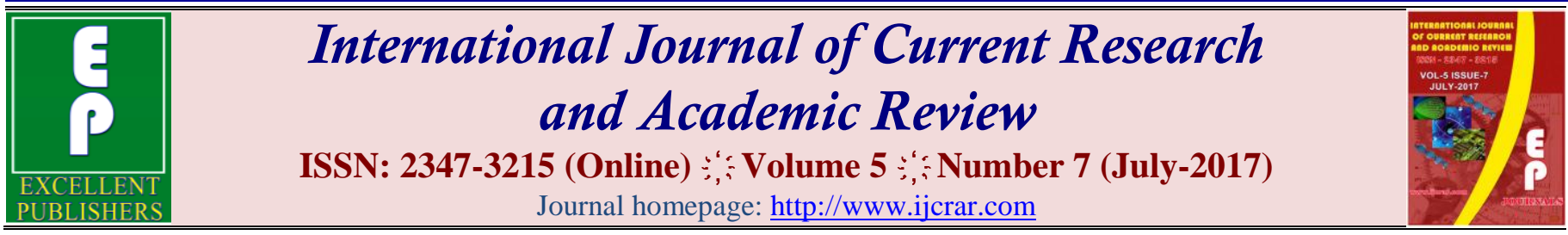

doi: $\underline{\text { https://doi.org/10.20546/ijcrar.2017.507.011 }}$

\title{
Optimization of Biomass Production of Two Ectomycorrhizal Fungi (Lactarius quieticolor and Rhizopogon roseolus) for the Future Pinus radiata Nursery Inoculation
}

\author{
Daniel Chávez $^{1 *}$, Ángela Machuca ${ }^{1}$ and Carolina Aguirre ${ }^{2}$ \\ ${ }^{1}$ Department of Plant Sciences and Technology, School of Sciences and Technology, Campus Los Ángeles, \\ Universidad de Concepción, Chile \\ ${ }^{2}$ Environmental Chemistry Department, Faculty of Sciences, Universidad Católica Ssma. Concepción. P.O. Box 297, \\ Concepción, Chile \\ *Corresponding author
}

\section{Abstract}

The growing interest in mycelial biomass for its application in nurseries has led to the creation of inoculum production programs in New Zealand, Australia, the United States, and Chile, where the advantages of mycorrhizal inoculation have been demonstrated in plant morphological and physiological parameters. However, the mycelial biomass yields produced with these fungi through traditional submerged culture are generally low. Therefore, the aim of this study was to optimize the variables $\mathrm{pH}$, temperature, and carbon source concentration required for maximum biomass production by the ectomycorrhizal fungi $L$. quieticolor and $R$. roseolus in liquid culture medium. The Box-Behnken (BB) design and response surface methodology (RSM) were used to establish the optimal conditions in the experimental area. Increases in biomass production of $1.2 \mathrm{~g} \mathrm{~L}^{-1}$ for $3.25 \mathrm{~g} \mathrm{~L}^{-1}$ for L. quieticolor $\left(\mathrm{pH} 5.5,24^{\circ} \mathrm{C}\right.$ and $20 \mathrm{~g}$ $\mathrm{L}^{-1}$ glucose) and 3.02 for $8.6 \mathrm{~g} \mathrm{~L}^{-1}$ for $R$. roseolus( $\mathrm{pH} 5.5,28^{\circ} \mathrm{C}$ and $30 \mathrm{~g} \mathrm{~L}^{-1}$ mannitol) were found in comparison to the control culture (pH $5.5,24^{\circ} \mathrm{C}_{\text {and }} 10 \mathrm{~g} \mathrm{~L}^{-1}$ glucose) for both fungi. This optimization is the first step required to scale biomass production by $L$. quieticolor and $R$. roseolus in bioreactors.
\end{abstract}

\section{Article Info}

Accepted: 02 June 2017

Available Online: 10 July 2017

\section{Keywords}

Biomass optimization,

Carbon sources,

Ectomycorrhiza,

$P$. radiata.

\section{Introduction}

Mycorrhizal symbiosis improves the health of plants, increasing protection against biotic factors (e.g. attack by pathogens) and abiotic factors (e.g. drought, salinity, metals), and improves the structure of the soil, promoting its aggregation (Karaki, 2006; Barea et al., 2011; Sousa et al., 2012; Trocha et al., 2016). It has also been verified that ectomycorrhizal fungi encourage plant growth in nurseries and help establish plantations in the field, facilitating interplant transfer of water as well as producing fungus of high economic value such as the truffles demanded in the European market (Sebastiana et al., 2013; Sánchez-Zabala et al., 2013; Chávez et al., 2014; Prieto et al., 2016; Iotti et al., 2016). Pinus radiata D. Don is planted on more than 1.5 million ha of Chilean territory, being one of the most important lumber species (Mead, 2013). There are approximately 32 fungal species in Chile associated with pine plantations found at different stages of growth (Garrido, 1986; Palacios et al., 2012). Among the important ectomycorrhizal fungi in the central southern zone of Chile associated with exotic 
plantations are the species Lactarius quieti color Romagn. And Rhizopogon roseolus (Corda) Th. Fr., both of which play important ecological roles in $P$. radiata plantations. Both species naturally form associations with $P$. radiata; however, $R$. roseolus does so during the young stage of the plants and L. quieticolor in the more adult stage. Currently, different inoculum types have been developed for the application of these species in nurseries, with the highest percentages of mycorrhization being obtained through the application of liquid mycelial inoculum (Chávez et al., 2009; Sánchez-Zabala et al., 2013; Pereira et al., 2014). But mycelium yields obtained by traditional submerged culture are relatively low, thus explaining the growing interest in improving mycelial biomass production through the study of culture variables such as $\mathrm{pH}$, temperature, nutrient concentration, and stirring rate, among others. Statistical experimental designs such as the Box-Behnken (BB) design and response surface methodology (RSM) particularly help in achieving this goal. As a statistical tool and mathematical, RSM aids in constructing models that identify effective factors, evaluate interactions, select the optimal conditions for the study variables, and quantify the relationships between one or more response measures, as well as allowing a consistent response with a limited number of trials (Avishek and Arun, 2008; Liyana-Pathirana and Shahidi, 2005). In this context, the purpose of this study was to determine the optimal conditions of $\mathrm{pH}$, temperature, and carbon source concentration for the mycelial biomass production of the ectomycorrhizal fungi $L$. quieticolor and $R$. roseolus in liquid culture medium. Prior to optimization, the best culture medium and type of carbon source were selected for each of the fungal species. Optimization of biomass production is the first step required for the future scaling of these fungal cultures in a bioreactor for the controlled mycorrhization of a large number of nursery plants.

\section{Materials and Methods}

\section{Experimental design}

RSM was used for the optimization(Chacín, 2000; Montgomery, 2002), making it possible to predict the system's response to each of the factors considered in the experimental area. The optimization process essentially involves three main steps: i) conducting the statistically designed experiments, ii) estimating the coefficients of a mathematical model and predicting the response, and iii) adequately verifying the model. The variables in this study were $\mathrm{pH}$, temperature, and carbon source concentration (glucose, mannitol, or sucrose, depending on the fungal species used), whereas the observed response was the total biomass produced after the incubation period. The response predicted $(\mathrm{Y})$ by the model can be generally expressed from Equation(1).

$Y=B_{0}+\sum_{i=1}^{k} B_{i} X_{i}+\sum_{i=j=1}^{k} B_{i j} X_{i} X_{j}$

In this study, $k$ takes the value of 3 as there are three variables $(\mathrm{pH}$, temperature, and carbon source concentration), and thus Equation (2) becomes:

$$
Y=B_{0}+B_{1} X_{1}+B_{2} X_{2}+B_{3} X_{3}+B_{12} X_{1} X_{2}+B_{13} X_{1} X_{3}+B_{23} X_{2} X_{3}+B_{11} X_{1}^{2}+B_{22} X_{2}^{2}+B_{33} X_{3}^{2}
$$

Where $X_{1}, X_{2}$, and $X_{3}$ are the input variables, $\mathrm{pH}$, temperature, and carbon source concentration, respectively; $B_{0}$ is a constant; $B_{1}, B_{2}$, and $B_{3}$ linear coefficients; $B_{12}, B_{13}$, and $B_{23}$ cross product or interaction coefficients; $B_{11}, B_{22}$, and $B_{33}$ are quadratic coefficients. The low, medium, and high values of each variable $(\mathrm{pH}$, temperature, and carbon source concentration) were coded as $-1,0$, and 1, respectively (Figure 1) and are shown together with the $\mathrm{BB}$ experimental design in Table1.The data were obtained from the program Modde 4.0 (Umetri, Umeå, Sweden). The statistical method of squared minimums was used to determine the regression coefficients of each of the terms of the functions that describe the behavior of the "biomass" response for $L$. quieticolor and $R$. roseolus in the intervals established for the multifactorial planning variables. The determination coefficient $\left(R^{2}\right)$ is the fraction of response variation explained by the model. The prediction coefficient $\left(\mathrm{Q}^{2}\right)$ is the fraction of response variation that can be predicted by the model and provides the best summary of model fit. R2-Q2 is an underestimate of the goodness of fit of the model.

\section{Fungal species}

Two ectomycorrhizal species belonging to the culture collection of the Fungi Biotechnology Laboratory at the Universidad de Concepción, Los Ángeles Campus were used: Rhizopogonroseolus (Corda) Th. Fr. and Lactariusquieticolor Romagn (Chávez et al., 2015). Mycelial agar pieces from the stock cultures were transferred to dishes with modified Melin-Norkrans 
(MMN) medium (Marx, 1969) and Biotin-Aneurin-Folic acid agar (BAF) (Moser,1960) and incubated for 20 days at $24^{\circ} \mathrm{C}$ to obtain active mycelia for the following trials.

\section{Selection of culture medium and carbon source}

The effect of the MMN and BAF media as well as of the carbon sources mannitol, glucose, and sucrose $\left(10 \mathrm{~g} \mathrm{~L}^{-1}\right)$ on the growth of the ectomycorrhizal fungi were assessed in order to choose the most suitable culture medium and carbon source for the subsequent optimization analysis of the culture variables. Erlenmeyer flasks $(100 \mathrm{~mL})$ containing $40 \mathrm{~mL}$ of liquid culture medium were inoculated with two mycelial agar discs (5 mm diameter) in triplicate and incubated at $24^{\circ} \mathrm{C}$ for 30 days. Once the incubation period was finished, the biomass was determined by the dry weight of the mycelia (mg).

\section{Growth kinetics}

Once the culture medium and carbon source were chosen for each fungal species, kinetic growth was tested at $\mathrm{pH}$ 5.5 and $24^{\circ} \mathrm{C}$ for 35 days under static and agitated $(120$ $\mathrm{rpm})$ conditions, and the specific growth rate $(\mu)$, time of cell duplication (Tdup) (time of duplication of biomass)and culture time when the stationary growth phase began were determined. Erlenmeyer flasks (100 $\mathrm{mL}$ ) containing $40 \mathrm{~mL}$ of liquid medium was inoculated in triplicate with two mycelial agar discs $(5 \mathrm{~mm}$ diameter) of each fungal species. Every 5 days, the mycelium grown in each flask was recovered by filtration and dried at $60^{\circ} \mathrm{C}$ until constant weight.

\section{Growth optimization of $L$. quieticolor and $R$. roseolus}

Growth optimization of the fungal species in liquid culture medium was conducted under orbital agitation $(120 \mathrm{rpm})$ and the variables $\mathrm{pH}$, temperature, and carbon source were evaluated (Table 1 and Figure 1). In order to evaluate the effect of the different carbon source concentrations $\left(20\right.$ to $40 \mathrm{~g} \mathrm{~L}^{-1}$ of glucose or mannitol, as appropriate) on the growth of the fungi, $\mathrm{BAF}$ medium was used, the composition of which in $\mathrm{g} \mathrm{L}^{-1}$ was: $\mathrm{CaCl}_{2}$ $0.2, \mathrm{KH}_{2} \mathrm{PO}_{4} 0.75, \mathrm{MgSO}_{4}$ x $7 \mathrm{H}_{2} \mathrm{O} 0.5, \mathrm{MnSO}_{4} 0.005$, $\mathrm{ZnSO}_{4} 0.001, \mathrm{FeCl}_{3} \times 7 \mathrm{H}_{2} \mathrm{O}$ 0.01, peptone 6.315, yeast extract 0.2 , thiamin 0.0005 , biotin 0.00001 , inositol 0.05 and folic acid 0.0001. The carbon source was glucose for $L$. Quieticolor and mannitol for $R$. roseolus, according to the results of the previous trials. The optimization was carried out in triplicate using Erlenmeyer flasks (100 $\mathrm{mL}$ ) containing $40 \mathrm{ml}$ of culture medium and two mycelial agar discs ( $5 \mathrm{~mm}$ diameter) as inoculum with a total culture time of 30 days.

\section{Evaluation of the biomass during the optimization stage}

At each collection, the mycelia were filtered through filter paper and dried at $60^{\circ} \mathrm{C}$ for $48 \mathrm{~h}$, after which the dry weight $(\mathrm{g})$ was determined. The residual volume of each culture medium in each Erlenmeyer flask was also measured. From these data the biomass concentration (g $\mathrm{L}^{-1}$ ) produced in each trial was calculated using the following formula:

$\mathrm{X}=\frac{\mathrm{B} 1-\mathrm{B} 2}{\mathrm{~V}}$

Where, $\mathrm{X}$ corresponds to the biomass concentration $\mathrm{g} \mathrm{L}^{-1}$, $\mathrm{B} 1$ to the mass of the dry sample plus the filter paper $(\mathrm{g})$, $\mathrm{B} 2$ to the mass of the filter paper $(\mathrm{g})$ and $\mathrm{V}$ to the residual volume of the culture medium $(\mathrm{L})$.

\section{Data analysis}

A factor analysis was applied for the response variable biomass. The analyzed factors were culture medium (BAF and MMN) and different carbon sources (glucose, sucrose, and mannitol). The data were subjected to an analysis of variance and the comparison of means was calculated according to the Tukey test $(P<0.05)$. For data analysis, the software Statistica v. 6.0 was used. For optimization, the biomass data expressed in $\mathrm{g} \mathrm{L}^{-1}$ collected from the 15 trials were subjected to a regression analysis using RSM employing the BB experimental design (Box and Behnken, 1960; Ferreira et al., 2007).

\section{Results and Discussion}

Mycelial biomass production of $L$. quieticolor and $R$. roseolus in liquid culture medium

L. quieticolor exhibited a greater biomass production in the BAF-glucose medium (47 mg, equivalent to $1.2 \mathrm{~g} \mathrm{~L}^{-}$ ${ }^{1}$ ), showing significant differences with all the other treatments. For $R$. roseolus, the better culture medium and carbon source was BAF-mannitol (115 mg, equivalent to $3.02 \mathrm{~g} \mathrm{~L} \mathrm{~L}^{-1}$ ), presenting significant differences $(\mathrm{P}<0.05)$ with the other carbon sources (Figure 2). 
Growth kinetics of $L$. quieticolor and $R$. roseolus under static and agitated conditions

When comparing the culture conditions (static and agitated) for the two fungal species, it was observed that the agitated condition encouraged mycelial biomass production (Figure 3). Between 15-30 days, $L$. quieticolor increased biomass production under constant agitation with a specific rate $(\mu)$ of 0.09 and 7 days of Tdup compared to the 13 days under static condition. At 25 days of culture, $R$. roseolus displayed a considerable increase in biomass production under agitation with a $\mu$ of 0.121 and a Tdup of 6 days, whereas under static condition, the duplication was generated at day 8.From the growth kinetics, days under agitation were established for the optimization assays.

\section{Optimization}

The growth of $L$. quieticolor and $R$. roseolus was sensitive to slight alterations in the factors such as $\mathrm{pH}$, temperature, and carbon source concentration. The effect of these factors on fungi growth was studied in relation to the total biomass produced expressed ing $\mathrm{L}^{-1}$. $L$. quieticolor presented the maximum biomass production with treatment6 $\left(3.25 \mathrm{~g} \mathrm{~L}^{-1}\right)$ and $R$. roseolus with treatment $4\left(8.60 \mathrm{~g} \mathrm{~L}^{-1}\right)$ (Table 2$)$. The regression equation obtained after the analysis of variance showed the biomass produced to be a function of the three study factors. Therefore, the predicted response $Y$ could be obtained by solving the quadratic equation (2), obtaining:

$Y_{1}=2.29+0.600 X_{1}-0.435 X_{2}+0.080 X_{3}-$ $0.240 X_{1}^{2}-0.375 X_{2}^{2}+0.328 X_{3}^{2}-0.170 X_{1} X_{2}-$ $0.038 X_{1} X_{3}-0.006 X_{2} X_{3}$

$Y_{2}=6.72+0.883 X_{1}+0.173 X_{2}+0.485 X_{3}-$ $0.464 X_{1}^{2}+0.517 X_{2}^{2}-0.195 X_{3}^{2}+0.458 X_{1} X_{2}-$ $0.427 X_{1} X_{3}-0.468 X_{2} X_{3}$

Where $Y_{1}$ and $Y_{2}$ were the predicted biomass of $L$. quieticolor and $R$. roseolus, respectively. The coefficients of Equations 3 and 4 are enumerated in Table 3. It can be noted that $\mathrm{pH}$ was the variable with the greatest effect on the biomass production by both ectomycorrhizal fungi. The summary of the analysis of variance for the response variable biomass is in Table 4. Based on the results, it may be stated that the model fit is good since the value of $R^{2}=0.85$ is close to 1 , in particular, $85 \%$ of the variability of the variable $\mathrm{Y}$ is explained by the adjusted regression model. In addition, the $p$ value in the general regression is significant at 5\%, thus demonstrating that the model is adequate in the approximation of the RSM of the experimental design.

Analysis of the variables $\mathrm{pH}$ and temperature revealed that as the $\mathrm{pH}$ increased (from 3.5 to 5.5) and the temperature decreased (from 28 to $20^{\circ} \mathrm{C}$ ), there was an increase in biomass production by L. quieticolor (Figure 4A). In contrast, when the temperature decreased (from 24 to $20^{\circ} \mathrm{C}$ ) and the glucose concentration increased (from 30 to $40 \mathrm{~g} \mathrm{~L}^{-1}$ ), the mycelial biomass production by the fungus increased (Figure 4B). When analyzing the variables $\mathrm{pH}$ and glucose concentration, maximum values of biomass production were observed at the highest $\mathrm{pH}$ values and at a concentration of 20 or $40 \mathrm{~g} \mathrm{~L}^{-1}$ glucose; however, when $30 \mathrm{~g} \mathrm{~L}^{-1}$ glucose was used, biomass production dropped (Figure 4C). In the case of $R$. roseolus, as the $\mathrm{pH}$ rose (from 4.5 to 5.5 ) to $28^{\circ} \mathrm{C}$, optimal biomass production values were observed(Figure 4D). When the different concentrations of mannitol interacted with the temperature, the biomass increased at a low temperature $\left(20^{\circ} \mathrm{C}\right)$ and at a high concentration of mannitol $\left(40 \mathrm{~g} \mathrm{~L}^{-1}\right)$. However, when the $\mathrm{pH}$ and the different concentrations of mannitol interacted, a directly proportional relation between the increase in the biomass of $R$. roseolus, the $\mathrm{pH}$, and the carbon source concentration was observed (Figure 4F).

The use of statistical models to optimize fungal biomass production and obtain metabolites has increased of late. Examples of this include research being conducted on the entomopathogenic fungus Cordyceps militaris and Metarhizium rileyi for biomass production (Hsieh et al., 2009; Cui and Yuan, 2011; Song et al., 2017), saprophytic fungi Lentinus squarrosulus (Ahmad et al., 2013) for mycelium and exopolysaccharide production, Ganoderma lucidum for phenolic compound production and biomass(Zárate et al., 2013; Goh et al., 2016), Pleurotus sp. for enzyme production (Saravanakumar et al., 2010) and Filamentous Fungi for Extracellular Lipase Production (Gaurav et al., 2017). Nonetheless, statistical models for research into the optimization of biomass production or metabolites by ectomycorrhizal fungi have scarcely been used (Srinivasan et al., 2000; Liu et al., 2008). For these, several selection criteria are required, particularly when the ultimate goal is the production of large amounts of biomass for the inoculation of plants on a large scale. The selection criteria include the variables $\mathrm{pH}$, concentration and type of carbon source, and culture temperature, which are of great significance in mycelial biomass production. 
In this study, the sugar alcohol mannitol, the hexose glucose, and the disaccharide sucrose were used as carbon sources. L. quieticolor produced the largest amount of biomass in the BAF-glucose medium, whereas $R$. roseolus presented the greatest biomass production in the same BAF medium, but in the presence of mannitol. Under these conditions, the biomass produced by $R$. roseolus was approximately more than double of what was produced by L. quieticolor. Although both species are ectomycorrhizal, they displayed a clear difference in terms of carbon source requirements for optimal biomass production. Studies conducted on the ectomycorrhizal fungi Infundibulicybe geotropa (Bull.) Harmaja, Tricholoma anatolicum H.H. Doğan \& Intini and Lactarius deliciosus (L.) Gray, all of epigeous fructification, showed that the greatest mycelial biomass production by $I$. geotropa was obtained using fructose; however, with $T$. anatolicum and $L$. deliciosus, this occurred using glucose (Akatal et al., 2012; Gomez et al., 2016). This is consistent with the results obtained with L. quieticolor, which although it produced the greatest amount of biomass in glucose, when it was cultivated in mannitol the amount of biomass was high. Glucose is a carbon source that is easily metabolized by most microorganisms, incorporating it into their metabolism for the rapid production of energy for cell processes (Deacon, 2006; Jonathan and Fasidi, 2001). Ectomycorrhizal fungi transform sugars produced and obtained from plants into mannitol or trehalose to incorporate them into their metabolism (Smith and Read, 2008). Mannitol performs important functions as a form of carbon storage and reducing power, in addition to being stored in vacuoles for the regulation of cell $\mathrm{pH}$ (Deacon, 2006). A better use of mannitol by $R$. roseolus could explain its greater production of fungal biomass than L. quieticolor.

Culture temperature is another external factor that plays a significant role in the growth of ectomycorrhizal fungi. Most fungi are mesophilic, which commonly grow in a temperature range between 10 and $40^{\circ} \mathrm{C}$ (Jonathan and Fasidi, 2001), and most ectomycorrhizal fungi are in this group. Within the growth temperature range, different degrees of tolerance can be observed, and often the increase in temperature can cause a decrease in fungal growth and sometimes the total cessation (Srinivasan et al., 2000). One exception among the ectomycorrhizal fungi is the case of $P$. tinctorius, with the ability to grow at temperatures between 40 and $42^{\circ} \mathrm{C}$, and with a thermal death point of the hyphae at $45^{\circ} \mathrm{C}$ (Hung and Chein, 1995). For the two species in this study, the optimum temperature for biomass production was found within the normal range of the mesophilic fungi, with the optimum temperature of $R$. roseolus $\left(28^{\circ} \mathrm{C}\right)$, being higher than that of L. quieticolor $\left(24^{\circ} \mathrm{C}\right)$. The optimum temperatures that these two fungal species present make them good candidates for biomass production on a large scale in a bioreactor due to the low energy requirement needed to maintain the temperature control during the culture. Moreover, the $\mathrm{pH}$ was the most significant variable in the optimization process in vitro. The optimum $\mathrm{pH}$ of $R$. roseolus and L. quieticolor for biomass production was 5.5, which is related to the fact that the soils where these species are developed are slightly acidic.

When evaluating growth kinetics, it was corroborated that agitation stimulated fungal biomass production. This may be related to a homogenous oxygenation in the flasks and at the same time to a continuous fragmentation of the mycelium, thereby generating new points of active growth and allowing a greater mass transfer of the nutrients towards the fungi (Teoh et al., 2010; Teoh and Don, 2012). The highest specific growth rate $(\mu)$ for $L$. quieticolor and $R$. roseolus was recorded in agitation (0.09 and $0.121 \mathrm{day}^{-1}$, respectively), with these rates being higher than those displayed under static conditions. The cell duplication time (Tdup) is the time that mediates between two successive duplications, and in this case, it depended on the culture and the fungal species. For $L$. quieticolor and $R$. roseolus, the maximum cell duplication time was 7 and 6 days, respectively, with agitation, much lower than the 13 and 8 days under static conditions.

RSM made it possible to determine the optimal conditions in the experimental area, obtaining an increase in biomass production of 1.2 for $3.25 \mathrm{~g} \mathrm{~L}^{-1}$ in the case of $L$. quieticolor at $\mathrm{pH} 5.5,24^{\circ} \mathrm{C}$ culture temperature, and $20 \mathrm{~g} \mathrm{~L}^{-1}$ of glucose concentration. For $R$. roseolus, the increase in biomass was 3.02 for $8.6 \mathrm{~g} \mathrm{~L}^{-1}$ at $\mathrm{pH} 5.5,28^{\circ} \mathrm{C}$ culture temperature, and $30 \mathrm{~g} \mathrm{~L}^{-1}$ mannitol concentration. This is a similar increase of 2.71 and 2.85 times in biomass production for L. quieticolor and $R$. roseolus, respectively, under optimized conditions. For the ectomycorrhizal fungus $P$. tinctorius (Srinivasan et al., 2000), an optimum growth range was found at $\mathrm{pH} 5.8-6$ and a temperature of $29-30^{\circ} \mathrm{C}$; when cultivated between 40 and 45 days in these conditions, the maximum biomass production was $1.13 \mathrm{~g} \mathrm{~L}^{-1}$, far below what was reported for $L$. quieticolor and $R$. roseolus and mainly due to the slow growth of $P$. tinctorius in artificial culture media. Other biomass optimization processes have found a 1.4-fold increase in 
the biomass production of the saprophytic fungus $C$. versicolor (Wang et al., 2012) and 1.9-fold in the entomopathogenic fungus $C$. militaris (Ahmad et al.,
2013). This underscores the importance of applying statistical designs to produce fungal biomass.

Table.1 Three-factor Box-Behnken experimental designs

\begin{tabular}{cccc}
\hline Trial N & pH & $\begin{array}{c}\text { Temperature } \\
\left({ }^{\circ} \mathrm{C}\right)\end{array}$ & $\begin{array}{c}\text { Glucose/Mannitol } \\
\left(\mathrm{g} \mathrm{L}^{-1}\right)\end{array}$ \\
\hline 1 & $3.5(-1)$ & $20(-1)$ & $30(0)$ \\
2 & $5.5(1)$ & $20(-1)$ & $30(0)$ \\
3 & $3.5(-1)$ & $28(1)$ & $30(0)$ \\
4 & $5.5(1)$ & $28(1)$ & $30(0)$ \\
5 & $3.5(-1)$ & $24(0)$ & $20(-1)$ \\
6 & $5.5(1)$ & $24(0)$ & $20(-1)$ \\
7 & $3.5(-1)$ & $24(0)$ & $40(1)$ \\
8 & $5.5(1)$ & $24(0)$ & $40(1)$ \\
9 & $4.5(0)$ & $20(-1)$ & $20(-1)$ \\
10 & $4.5(0)$ & $28(1)$ & $20(-1)$ \\
11 & $4.5(0)$ & $20(-1)$ & $40(1)$ \\
12 & $4.5(0)$ & $28(1)$ & $40(1)$ \\
13 & $4.5(0)$ & $24(0)$ & $30(0)$ \\
14 & $4.5(0)$ & $24(0)$ & $30(0)$ \\
15 & $4.5(0)$ & $24(0)$ & $30(0)$ \\
\hline
\end{tabular}

Table.2 Experimental and theoretical predicted values for biomass expressed in $\mathrm{g} \mathrm{L}^{-1}$

\begin{tabular}{lllll}
\hline & \multicolumn{2}{l}{$\begin{array}{l}\text { Lactarius } \\
\text { quieticolor }\end{array}$} & \multicolumn{2}{l}{$\begin{array}{l}\text { Rhizopogon } \\
\text { roseolus }\end{array}$} \\
$\begin{array}{l}\text { Trial } \\
\mathrm{n}^{\circ}\end{array}$ & Actual & Predicted & Actual & Predicted \\
\hline 1 & 1.21 & 1.34 & 5.86 & 6.18 \\
2 & 2.79 & 2.88 & 6.66 & 7.03 \\
3 & 0.90 & 0.81 & 5.97 & 5.61 \\
4 & 1.80 & 1.67 & 8.60 & 8.29 \\
5 & 2.01 & 1.66 & 4.41 & 4.27 \\
6 & 3.25 & 2.94 & 7.08 & 6.89 \\
7 & 1.58 & 1.90 & 5.90 & 6.09 \\
8 & 2.67 & 3.02 & 6.86 & 7.00 \\
9 & 2.37 & 2.59 & 6.08 & 5.92 \\
10 & 1.30 & 1.73 & 6.69 & 7.20 \\
11 & 3.20 & 2.76 & 8.33 & 7.82 \\
12 & 2.10 & 1.88 & 7.07 & 7.23 \\
13 & 2.27 & 2.29 & 6.65 & 6.72 \\
14 & 2.27 & 2.29 & 6.60 & 6.72 \\
15 & 2.32 & 2.29 & 6.92 & 6.72 \\
\hline
\end{tabular}


Table.3 Model coefficients

\begin{tabular}{lcc}
\hline & \multicolumn{2}{c}{ Biomass } \\
Variables & L. quieticolor & $R$. roseolus \\
\hline$B_{0}$ & 2.290 & 6.720 \\
$B_{1}$ & 0.600 & 0.883 \\
$B_{2}$ & -0.435 & 0.173 \\
$B_{3}$ & 0.080 & 0.485 \\
$B_{11}$ & -0.240 & -0.464 \\
$B_{22}$ & -0.375 & 0.517 \\
$B_{33}$ & 0.328 & -0.195 \\
$B_{12}$ & -0.170 & 0.458 \\
$B_{13}$ & -0.038 & -0.427 \\
$B_{23}$ & -0.006 & -0.468 \\
$\boldsymbol{Q}^{\mathbf{2}}$ & 0.73 & 0.74 \\
$\boldsymbol{R}^{2}$ & 0.85 & 0.85 \\
\hline
\end{tabular}

Table.4 Regression analysis for the amount of biomass (quadratic response surface model fitting)

A) L. quieticolor and B) R. roseolus

\begin{tabular}{|c|c|c|c|c|c|c|c|c|}
\hline (A & & & & & (B & & & \\
\hline Source & $\begin{array}{l}\text { Sum of } \\
\text { squares }\end{array}$ & $\begin{array}{l}\text { Degree } \\
\text { of } \\
\text { freedom }\end{array}$ & $\begin{array}{l}\text { Mean } \\
\text { squares }\end{array}$ & $\begin{array}{l}\text { F value } \\
(P< \\
0.001)\end{array}$ & \begin{tabular}{|l} 
Sum of \\
Squares \\
\end{tabular} & $\begin{array}{l}\text { Degree } \\
\text { of } \\
\text { freedom }\end{array}$ & $\begin{array}{l}\text { Mean } \\
\text { squares }\end{array}$ & $\begin{array}{l}\text { F value } \\
(P< \\
0.001)\end{array}$ \\
\hline Model & 17.3 & 9 & 1.920 & 21.2 & 38.62 & 9 & 4.291 & 21.8 \\
\hline Residual & 3.170 & 35 & 0.090 & & 6.867 & 35 & 0.196 & \\
\hline Lack of fit & 2.88 & 3 & 0.963 & 10.76 & 3.44 & 3 & 1.14 & 10.69 \\
\hline Pure error & 0.28 & 32 & 0.008 & & 3.43 & 32 & 0.107 & \\
\hline $\begin{array}{l}\text { Correlation } \\
\text { total }\end{array}$ & 20.276 & 44 & & & 45.48 & 44 & & \\
\hline
\end{tabular}

Fig.1 The low, middle, and high levels of the three variables under optimization (temperature, $\mathrm{pH}$, and carbon source concentration)

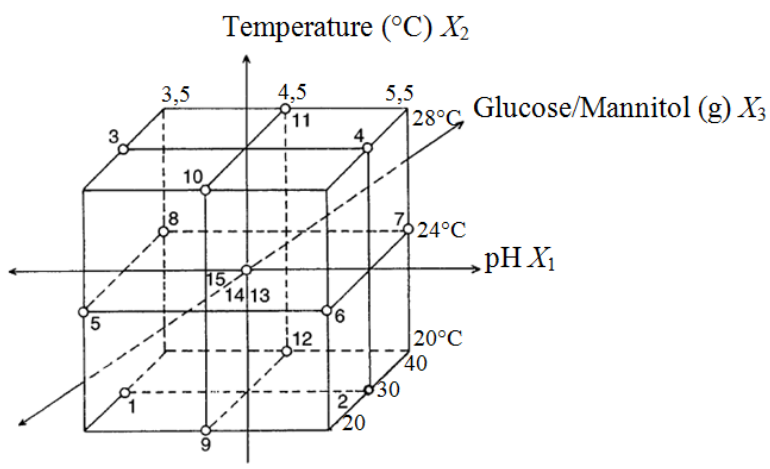


Fig.2 Production of mycelium biomass by (A) L. quieticolor and (B) R. roseolus cultivated in liquid medium BAF and $\mathrm{MMN}$, using mannitol, glucose, and sucrose as carbon sources $\left(10 \mathrm{gL}^{-1}\right)$. Incubation time: 30 days. WCS: without carbon source

A)

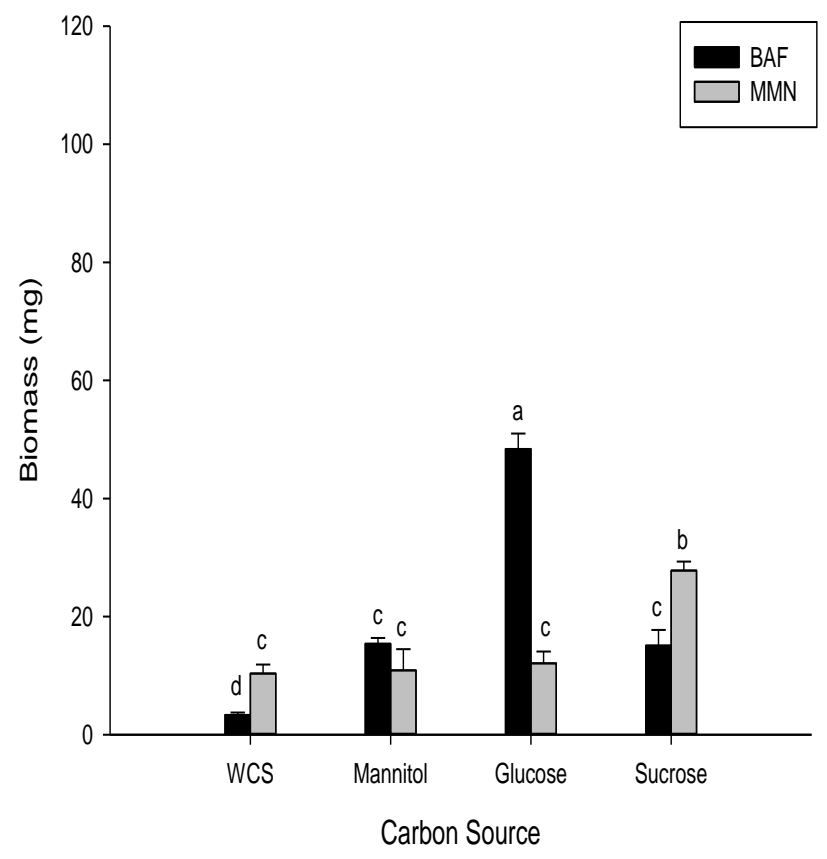

B)

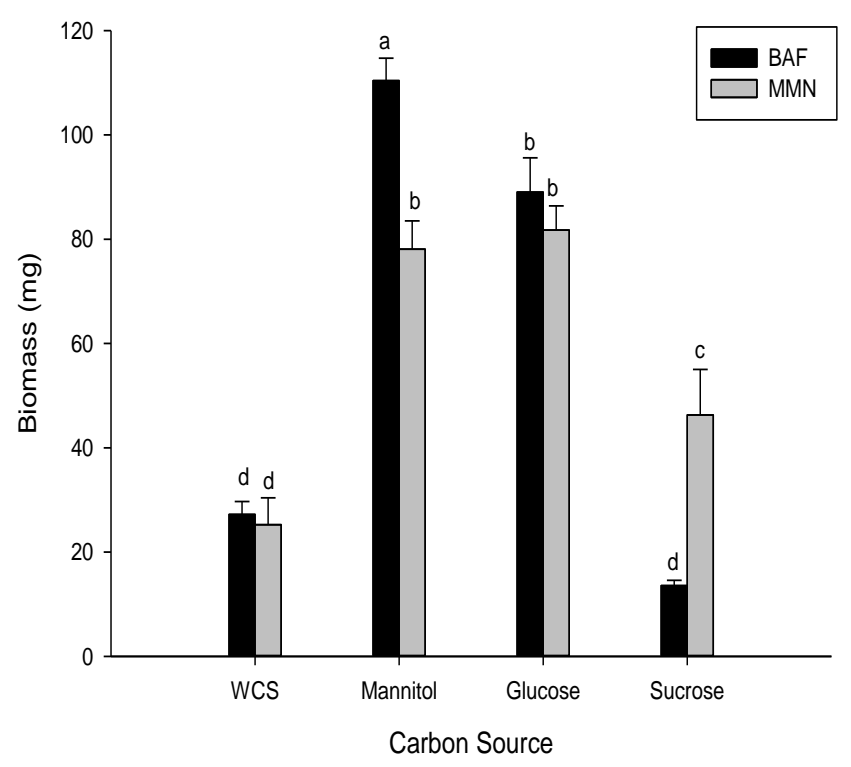

Fig.3 Growth kinetics at pH 5.5 for L. quieticolor (A) and R. roseolus (B) in agitated and static conditions. $\mu$ : specific growth rate. Tdup: time of cell duplication

A

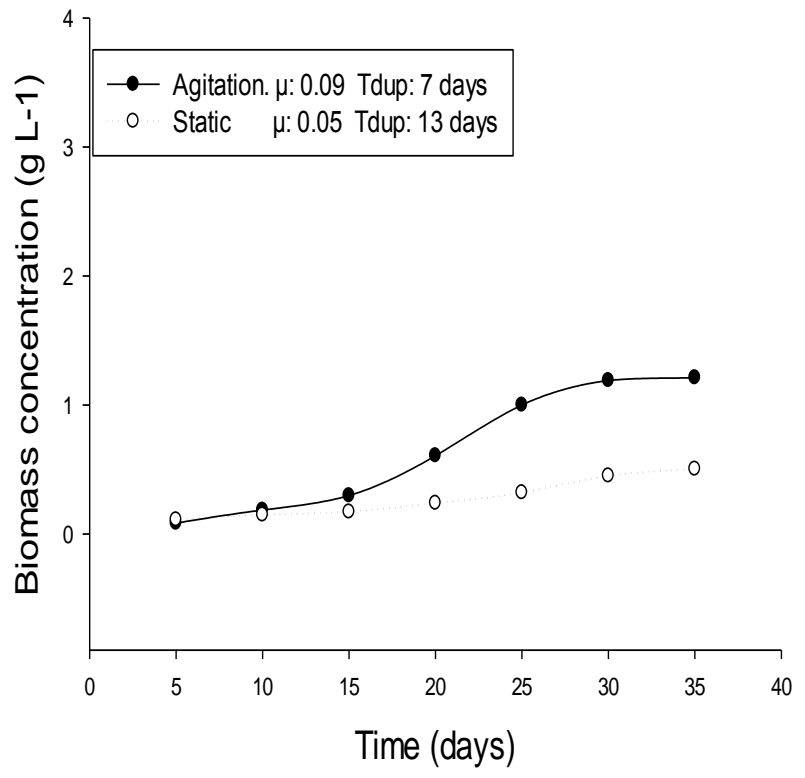

B

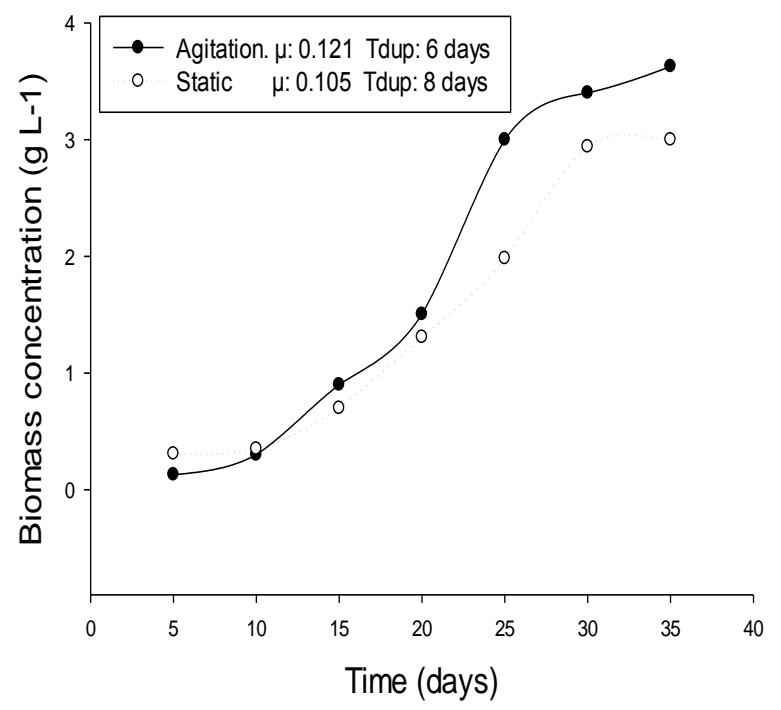


Fig.4 Response surface curve (3D plot) of mycelium biomass from L. quieticolor (A-C) and R. roseolus (D-F), showing the interaction between (A-D) $\mathrm{pH}$ and temperature, (B-E) carbon source and temperature and $(\mathrm{C}-\mathrm{F}) \mathrm{pH}$ and carbon source

A)
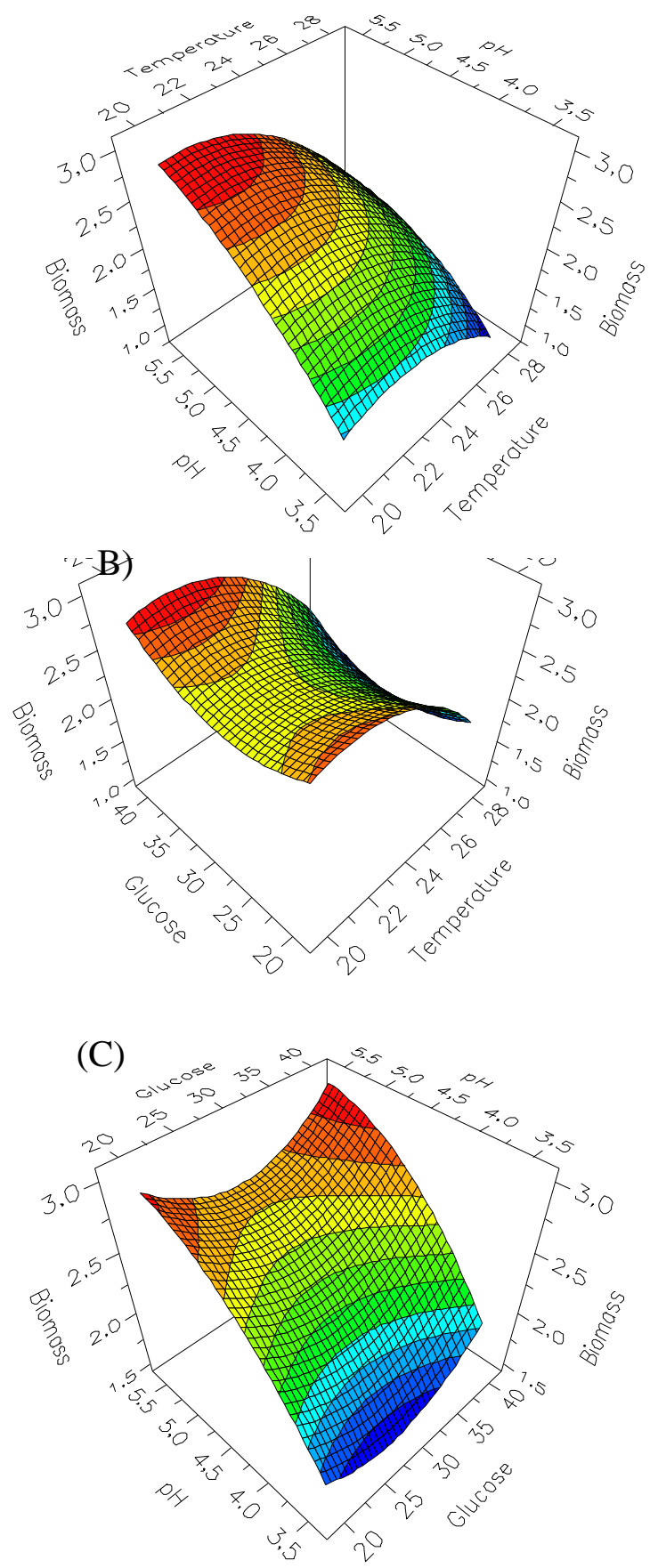

Although the statistics, $\mathrm{R}^{2}$ correlation coefficient, and $\mathrm{Q}^{2}$ predictivity (Table 3 ) represent the explanation rate of the total variability found in the response and the prediction rate that the model presents, respectively, these do not provide any information about the reliability

D)

E)
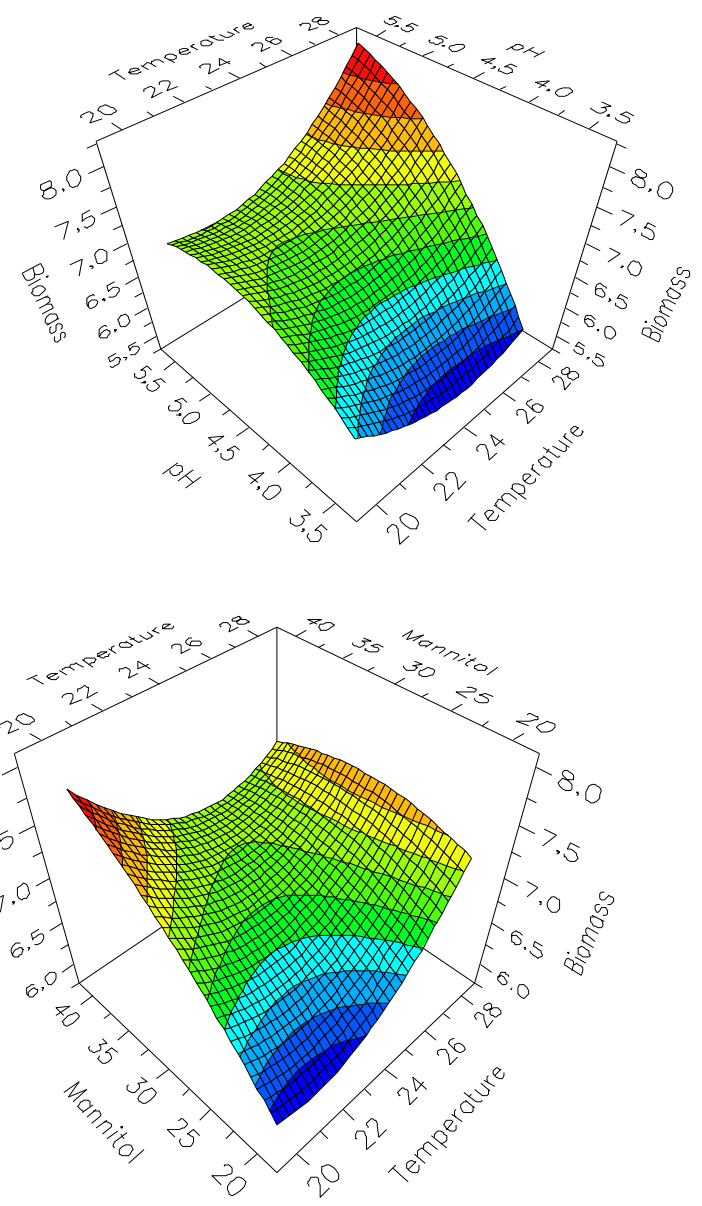

F)

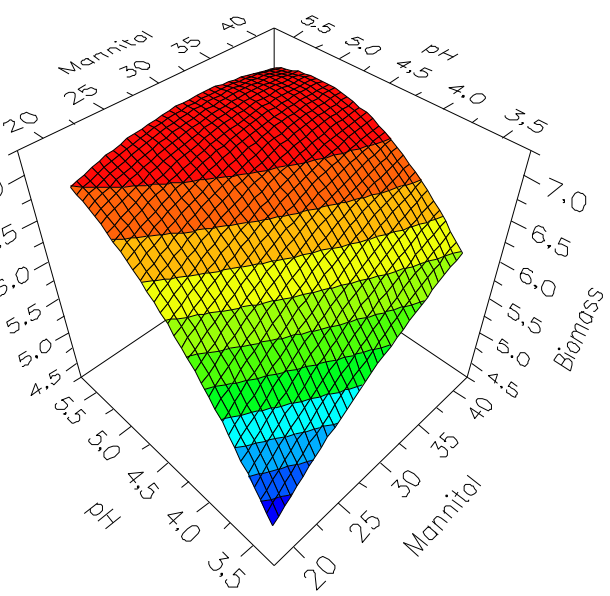

of the model. For this, the regression $\mathrm{F}$ (model) must be greater than the lack of fit F. Furthermore, the $P$ value of the regression must be less than 0.05 (Montgomery, 2002). Under these assumptions, the ANOVA (Table 4 A and $\mathrm{B})$ for the biomass production $\left(\mathrm{g} \mathrm{L}^{-1}\right)$ indicated that 
the model for both fungal species was satisfactory. Therefore, the response surface for the biomass in the optimization stage was statistically reliable. The response surface image helped to evaluate the effect of any combination of two factors on the fungi growth; therefore, for the effects of the interactions $\mathrm{pH}$ temperature, carbon source-temperature, and carbon source-pH, a favorable response could be achieved.

\section{Conclusion}

Through the optimization process using RSM, it was possible to establish the conditions of carbon source concentration, culture medium, $\mathrm{pH}$, and culture temperature for the maximum production of biomass in liquid medium under agitated conditions with $R$. roseolus and $L$. quieticolor, prior to determination of the best culture medium and carbon source. In the stage following this study, biomass production will be scaled to bioreactors, under the already optimized conditions, with the aim of obtaining large amounts of $R$. roseolus and $L$. quieticolor biomass for application in inoculation tests of $P$. radiata nursery plants.

\section{Acknowledgements}

Daniel Chávez would like to thank the Chilean National Council for Science and Technology CONICYT 21110038 for the assigned Postgraduate Grant.

\section{Disclosure statement}

No potential conflict of interest was reported by the author(s).

\section{References}

Ahmad, R., N.K. Al-Shorgani, A.A. Hamid, W.M. WanYusoff, and F. Daud. 2013. Optimization of medium components using response surface methodology (RSM) for mycelium biomass and exopolysaccharide production by Lentinus squarrosulus. Adv. Biosci. Biotechnol., 4: 10791085.

Akatal, I., F. Kalyoncu, M. HalilSolak, and K. Erbil. 2012. Growth of mycelium of three ectomycorrhizal macrofungi, Infundibulicybe geotropa, Tricholoma anatolicum and Lactarius deliciosus in culture media containing various carbon sources. Afr. J. Microbiol. Res., 6: 3042-3046.

Avishek, M. and Arun, G. 2008 Enhanced production of exocellular glucans ucrase from Leuconostoc dextranicum NRRL B-1146 using response surface methodology. Bioresour. Technol., 99: 3685-3691.

Barea, J.M., J. Palenzuela, P. Cornejo, I. Sánchez-Castro, C. Navarro-Fernández, A. López-García, R. Azcón, N. Ferrol, C. Azcón-Aguilar. 2011. Ecological and functional roles of mycorrhizas in semi-arid ecosystems of Southeast Spain, J. Arid Environ., 75: 1292-1301.

Box, G.E.P., and Behnken, D.W.1960. Some new three level designs for the study of quantitative variable. Technometrics, 2: 455-463.

Chacín, F. 2000. Diseño y análisis de experimentos para generar superficies de respuesta, Maracay: Universidad Central de Venezuela, Facultad de Agronomía, Venezuela.

Chávez, D., G. Pereira, A. Machuca.2009.Effect of inoculum type of three fungal species on the controlled mycorrhization of Pinus radiata seedlings. Bosque, 30: 4-9.

Chávez, D., Pereira, G., Machuca, A. 2014. Stimulation of Pinus radiataseedling growth using ectomycorrhizal and saprophytic fungi as biofertilizers. Bosque, 35: 57-63.

Chávez, D., A. Machuca, G.A. Torres-Mellado, C. Gallardo-Escárate, G. Palfner. 2015. Phylogenetic and mycogeographical aspects of Lactarius and Rhizopogon associated to Pinus radiata in southcentral Chile. Phytotaxa, 226: 177-187.

Cui, J.D., and YuanL.Q.2011. Optimization of Culture Conditions on Mycelial Grown in Submerged Culture of Cordyceps militaris. Int. J. Food Eng., 7: $1556-3758$.

Deacon, J. 2006. Fungal Biology, 4th ed., Blackwell Publishing Ltda.

Ferreira, S.L.C., R.E. Brunsb, H.S. Ferreira, G.D. Matosa, J.M Davida, G.C Brandão, E.G.P. Da Silva, L.A. Portugal, P.S. Dos Reis, A.S. Souzaa and W.N.L Dos Santos. 2007. Box-Behnken design: An alternative for the optimization of analytical methods. Analytica Chimica Acta, 2: 179-186.

Garrido, N. 1986. Survey of ectomycorrhizal fungi associated with exotic trees in Chile. Nova Hedwigia 43: 423-442.

Gaurav, K., S.S. Faujdar, P. Mehrishi, and S. Sharma. 2017. Screening and Optimization of Filamentous Fungi for Extracellular Lipase Production from Various Soil Samples Taken In and Around Shimla (HP), India. Int. J. Curr. Res. Aca. Rev., 5(1): 42-53.

Goh, Y., N.F. Marzuki, S.Y. Tan, S.S Tan, H.J. Tung, Y.K. Goh and K.J. Goh. 2016. Experimental mixture design as a tool to optimize the growth of 
various Ganoderma species cultivated on media with different sugars. Mycol., 7(1): 36-44.

Gómes, F., D. Suárez, R. Santos, M. Silva, D. Gaspar, and H. Machado. 2016. Mycorrhizal synthesis between Lactarius deliciosus and Arbutus unedo L. Mycorrhiza, 26: 177-188.

Hsieh, C.h., K.L. Tsai, I.L. Shih. 2007. Effects of culture conditions on the mycelial growth and bioactive metabolite production in submerged culture of Cordyceps militaris. Biochem. Eng. J., 33: 193-201.

Hung, L., and CheinC.Y.1995. Physiological studies on two ectomycorrhizal fungi Pisolithus tinctorius and Suillus bovinus. Trans Mycol. Soc. Japan, 19: 121122.

Iotti, M., F. Piattoni, P. Leonardi, I.R. Hall, A. Zambonelli. 2016. First evidence for truffle production from plants inoculated with mycelial pure cultures. Mycorrhiza, 26(7): 793-8.

Jonathan, S.G., and Fasidi, I.O.2001. Effect of carbon, nitrogen and mineral sources on growth of Psathyrella atroumbonata, Pegler. A Nigerian edible mushroom. Food Chem., 72: 479-483.

Karaki, G.N. 2006. Nursery inoculation of tomato with arbuscular mycorrhizal fungi and subsequent performance under irrigation with saline water. Scientia Horticulturae, 109: 1-7.

Liu, R.S., D.S. Li, H.M. Li, and Y.J. Tang.2008. Response surface modeling the significance of nitrogen source on the cell growth and Tuber polysaccharides production by submerged cultivation of Chinese truffle Tuber sinense. Process Biochem., 43: 868-878.

Liyana-Pathirana, C., and Shahidi, F.2005. Optimization of extraction of phenolic compounds from wheat using surface response methodology. Food Chem., 9: 347-356.

Marx, D.H. 1969. The influence of ectotrophic mycorrhizal fungi on the resistance of pine roots to pathogenic infection. Antagonism of mycorrhizal fungi to root pathogenic fungi and soil bacteria. Phytopathol., 59: 153-163.

Mead, D.J. 2013. Sustainable management of Pinus radiata plantations, vol 170: FAO Forestry Paper, Rome.

Montgomery, D.C. 2002. Diseño y Análisis de Experimentos, 2nd ed., Limusa, Wiley, México.

Moser, M. 1960. Die Gattung Phlegmacium. Die Pilze Mitteleupora, vol. 4: Bad Heilbrunn: J. Klinkhardt.

Palacios, Y., C. Hernández C, and G. Palfner. 2012. Comunidad ectomicorrícica en una cronosecuencia de Pinus radiata (Pinophyta: Pinaceae) en la VIII Región de Chile. Rev. Chil. Hist. Nat., 85: 61-71.
Pereira, G., J.L. Campos, D. Chávez, L. Anabalón, and C. Arriagada.2014.Caracterización del crecimiento miceliar del hongo ectomicorrícico Lactariusaff. deliciosus y su simbiosis con plántulas de Pinus radiata. Rev. Quebracho, 22: 30-39.

Prieto, I., A. Roldán, D. Huygens, M. Alguacil, J. Navarro-Cano, and J.I. Querejeta. 2016.Speciesspecific roles of ectomycorrhizal fungi in facilitating inter plant transfer of hydraulically redistributed water between Pinus halepensis saplings and seedlings. Plant and Soil, 1: 1-13.

Sánchez-Zabala, J., J. Majada, N. Martín-Rodrigues, C. Gonzalez-Murua, U. Ortega, M. Alonso-Graña, Orats Arana, and M.K. Duñabeitia. 2013. Physiological aspects underlying the improved out planting performance of Pinus pinaster A it. Seedlings associated with ectomycorrhizal inoculation. Mycorrhiza, 23: 627-640.

Saravanakumar, K., R. Saranya, A. Sankaranarayana, and V. Kaviyarasan. 2010. Statistical designs and response surface technique for the optimization of extra cellular Laccase enzyme production by using Pleurotus sp. Rec. Res. Sci. Technol., 2: 104-111.

Sebastiana, M., V.T. Pereira, A. Alcântara, M.S. Pais, A.B. Silva. 2013. Ectomycorrhizal inoculation with Pisolithus tinctorius increases the performance of Quercus suber L. (cork oak) nursery and field seedlings. New Forests, 44: 937-949.

Smith, S.E., and D.J. Read. 2008. Mycorrhizal Symbiosis. 3rd ed. Academic Press, London, UK.

Sousa, N.R., A.R. Franco, R.S. Oliveira, P.M. Castrom. 2012.Ectomycorrhizal fungi as an alternative to the use of chemical fertilisers in nursery production of Pinus pinaster. J. Environ. Manage., 95: 269-274.

Song, Z., Y. Lin, F. Du, Y. YinY, and Z. Wang. 2017. Statistical optimization of process variables and large-scale production of Metarhizium rileyi (Ascomycetes: Hypocreales) microsclerotia in submerged fermentation. Mycol., DOI: 10.1080/21501203.2017.1279688.

Srinivasan, M., K. Natarajan, and G. Nagajaran. 2000. Growth optimization of an ectomycorrhizal fungus with respect to $\mathrm{pH}$ and temperature in vitro using Design of Experiments. Bioprocess Eng., 22: 267273.

Teoh, Y.P., M.M. Don, and S. Ujang.2010.Cellulase Production by Pycnoporus sanguineus on Oil Palm Residues through Pretreatment and Optimization Study. J. Appl. Sci., 10: 1036-1043.

Teoh, Y.P., and DonM.M. 2012. Optimization of Parameters for Mycelia Growth by Schizophyllum 
commune and a Kinetic Model Study of its Growth Morphology. J. Appl. Sci., 12: 1100-1105.

Trocha, L.K., E. Weiser, P. Robakowski. 2016. Interactive effects of juvenile defoliation, light conditions, and interspecific competition on growth and ectomycorrhizal colonization of Fagus sylvatica and Pinus sylvestris seedlings. Mycorrhiza, 26: 4756.

Wang, F., Z. Jianchun, H. Limin, J. Shiru, B. Jianming, N. Shuang. 2012. Optimization of Submerged Culture Conditions for Mycelial Growth and

\section{How to cite this article:}

Daniel Chávez, Ángela Machuca, Carolina Aguirre. 2017. Optimization of Biomass Production of Two Ectomycorrhizal Fungi (Lactarius quieticolor and Rhizopogon roseolus) for the Future Pinus radiata Nursery Inoculation. Int.J.Curr.Res.Aca.Rev. 5(7), 76-87. doi: https://doi.org/10.20546/ijcrar.2017.507.011 